\title{
Risk Factors Associated with Infant Mortality in Owerri Metropolis, Imo State, Southeastern Nigeria
}

\author{
Nwaokoro Joakin Chidozie ${ }^{1,}$, Ibe Sally N. O. ${ }^{1}$, Ihenachor Chinenye A. ${ }^{2}$, Emerole Chima O. ${ }^{1}$, \\ Nwufo Regina C. ${ }^{1}$, Ebiriekwe Sabinus Chidubem ${ }^{3}$, Onwuliri Viola A. ${ }^{4}$ \\ ${ }^{1}$ Department of Public Health Technology, School of Health Technology, Federal University of Technology Owerri, Imo State, Nigeria \\ ${ }^{2}$ Central Registry Unit, Federal University of Technology, Owerri, Nigeria \\ ${ }^{3}$ Raw Materials Research and Development Council (RMRDC), Maitama, Abuja, Nigeria \\ ${ }^{4}$ Department of Biochemistry, Federal University of Technology, Owerri, Nigeria
}

\section{Email address:}

nwaokorojc@hotmail.com (Nwaokoro J. C.), sallyibe@yahoo.com (Ibe S. N. O.), c.ihenachor@gmail.com (Ihenachor C. A.), coemerole@yahoo.com (Emerole C. O.), chinyerenwufo@yahoo.com (Nwufo R. C.), sabhermis@yahoo.com (Ebiriekwe S. C.), violaonwuliri@yahoo.com (Onwuliri V. A.)

\section{To cite this article:}

Nwaokoro Joakin Chidozie, Ibe Sally N. O., Ihenachor Chinenye A., Emerole Chima O., Nwufo Regina C., Ebiriekwe Sabinus Chidubem, Onwuliri Viola A.. Risk Factors Associated with Infant Mortality in Owerri Metropolis, Imo State, Southeastern Nigeria. Science Journal of Public Health. Special Issue: Who Is Afraid of the Microbes. Vol. 3, No. 5-1, 2015, pp. 64-71. doi: 10.11648/j.sjph.s.2015030501.22

\begin{abstract}
Despite, new advances in medicine, infant mortality continues to threaten many families and the country in general. Investigation of the risk factors associated with infant mortality in Owerri metropolis, Imo State, Nigeria was therefore carried out. Selected hospitals in Owerri metropolis were used as study areas. A total of 200 respondents (health workers) were recruited for the study. Pre-tested structured questionnaires were administered to the respondents for data collection. Presentation and analysis of data were done using descriptive statistics and chi square test. Results obtained showed that prepregnancy factors (previous number of children, birth spacing, previous birth complications, Human Immunodeficiency Virus (HIV) infection, malnutrition, alcohol intake, level of mother's education, previous caesarian section), antenatal factors (low birth weight, gestational diabetes, failure to receive tetanus toxoid vaccine, congenital malformation, drinking alcohol, smoking or staying near a smoker, malaria in mother, obesity, feeding habit of a pregnant woman) and post natal factors (over weight of a baby, place of delivery, birth attendant, preterm birth, length of labour, placenta abnormalities, caesarian section, failure to have a wellness baby check, jaundice) were observed to contribute to infant mortality. There existed high significant difference among the parameters that were considered. Therefore, it was surmised that the parameters that were studied under pre-pregnancy, antenatal and post-natal risk factors contributed to infant mortality in Owerri, metropolis.
\end{abstract}

Keywords: Infant, Mortality, Risk Factors, Pregnancy

\section{Introduction}

Primary health care has been defined as essential health care based on practical, scientifically sound and socially acceptable methods and technology made universally accessible to individuals and families through their full participation and at a cost that the community and the country can afford to maintain at every stage of their development in the spirit of self reliance and self determination [1]. Infant mortality is defined as the death of an infant before his or her first birthday [2]. It is a useful indicator on the nation's health because it is often associated with other health factors such as maternal health, quality and accessibility of medical care and socio economic conditions [2]. Historically, infant mortality claimed a considerable percentage of children born, but rates have significantly declined in the West in modern times. This has been mainly due to improvements in basic health care, though high-technology medical advances have also helped. Infant mortality rate is commonly included as a part of standard of living evaluations in economies $[3,4,5]$. There are many different frameworks with which the effect of different determinants on childhood mortality may be considered. Demographic studies have distinguished between socioeconomic (exogenous) and biomedical (endogenous) factors. The effect of these exogenous variables are said to be indirect as they operate within the endogenous biomedical factors 
called proximate determinants [6]. Although, several studies by health actuaries exists on child mortality, evidence on why the rates is still high in Nigeria in spite of various action plans and interventions made remain sparse. Possibly, the cause of disease and death over which not much controversies and uncertainties exist is the total environment of man [7]. Malaria, acute respiratory infections, measles, and diarrhea which are today major causes of mortality for children under five are consequences from the environment. In developing countries like Nigeria, 1:8 children does not live to see his first birthday due to avoidable environmental threats, resulting into approximately 11 million avoidable childhood deaths yearly [8]. According to [9], environmental risk factors were estimated to account for about one-fifth of the total burden of disease in low income countries. The WHO [10] similarly, as reported in [11] revealed that in developing countries with high mortality rates, unsafe water, sanitation, hygiene and smoke from solid fuels were are among the high ranking causes of mortality. About 3\% (1.7 million) of the resulting deaths are attributable to environmental risk factors and child deaths account for about $90 \%$ of the total.

\subsection{Forms of Infant Mortality}

(1) Neonatal mortality: is newborn death occurring within 28 days postpartum. Neonatal death is often attributed to inadequate access to basic medical care, during pregnancy and after delivery [12]. This accounts for about half of infant deaths in our country, Nigeria. The neonatal mortality rate, (per 1000 live births) in Nigeria was last reported at 40 in 2010 [13].

(2) Post-neonatal mortality implies death of babies between 29 and 365 days of life [10]. The major contributors to post neonatal death are malnutrition, infectious disease, and problems with the home environment.

(3) Perinatal mortality involves deaths in the first week of life including still births. This is at an unacceptably high level in developing countries, especially those in sub-Saharan Africa (SSA) [14]. Recent estimates show that the perinatal mortality rate (PNMR) in developed regions of the world is about 10 per 1000 live births as against 50 per 1000 live births in less developed regions of the world. These figures are particularly troubling because the PNMR is known to be a key health status indicator of a community. Specifically, it is an important indicator of the quality of obstetric and pediatrics care available in any setting but at the same time it is a major contributor to overall childhood mortality [14].

\subsection{Nigeria Infant Mortality Rate}

This rate is often used as an indicator of the level of health in a country.

\subsubsection{Death of Newborns in Nigeria}

Nigeria has the highest absolute number of newborn deaths among countries in Africa, accounting for 255,500 of the 912,000 infants who die annually in Africa [15]. With infant mortality rate of 48/1000 live births, and over 700 newborn deaths each day, Nigeria ranks seventh among the ten African countries where newborns have the highest risk of dying. Infant deaths in Nigeria account for a quarter of under-five mortality [15]. Infectious conditions such as septicaemia, pneumonia and meningitis account for the greatest proportion $(42 \%)$ of deaths within the first month of life. Delivery- related complications, chiefly asphyxia and birth trauma account for 32\%, and pregnancy-related complications such as eclampsia, malaria, anemia, and malnutrition for the remaining $26 \%$ of neonatal deaths [16]. Pre term birth and low birth weight are most times also indicted as major causes of infant mortality in Nigeria.

\subsubsection{Pre-term Birth}

Although mortality falls with increasing gestational age, even infants born only a few weeks early have a substantially increased risk of death when compared with term infants. In 2006, the infant mortality rate for late preterm infants (34-36 weeks of gestation) was $7.08,2.9$ times the rate for term infants. Even within the term period, infants born at 37-39 weeks of gestation had mortality rates that were 28 percent higher than those for infants born at 40-41 weeks of gestation [15]. The stillbirth rate and perinatal, neonatal, and infant mortality rates have been reported to be significantly higher in the late-preterm group compared to the term group [17].

\subsubsection{Low Birth Weight}

According to the 2006 period infant mortality statistics from the linked birth/infant death data set, infant mortality rates were much higher for low birth weight (less than 2,500 grams) infants $(55.38$ per 1,000$)$ than for infants with birth weights of 2,500 grams or more (2.24). The infant mortality rate for very low birth weight (less than 1, 500 grams) infants was 240.44, more than 100 times the rate for infants with birth weights of 2, 500 grams or more [15]. Zeitlin, [18] also reported that mortality rate was significantly higher for infants with birth-weights $<25$ th percentile when compared with the 50th to 74th percentile. Kaushik, [8] found that although low birth weight babies accounted for $27.8 \%$ of the live births, they accounted for $79.5 \%$ of neonatal deaths

\subsection{Determinant Factors of Infant Mortality}

Infant mortality rate is an accepted global indicator of the health and socioeconomic status of a given population [19]. Neonatal health is said to be dependent on healthcare services, and post neonatal health is dependent on environmental factors. Hence, a high infant mortality rate is an indicator of unmet health care needs and unfavorable environmental factors. In a prospective study in a rural community in southwestern Nigeria, population 3, 308, infant mortality rate resulted in neonatal death rate accounting for $55.1 \%$ of all infant deaths, while post neonatal deaths accounted for $44.9 \%$ of the deaths. $44.4 \%$ of all neonatal deaths occurred within 24 hours of delivery while $74.1 \%$ of 
all neonatal deaths occurred in the first week of life and were perinatal deaths. In the study significantly more deaths occurred during the rainy season than in the dry season, suggesting environmental factors play a role in neonatal deaths. The commonest cause of death in the neonatal period was due to complications of low birth weight, while in the postnatal period it was due to infection. Hence, the high infant mortality rate in Nigeria is systemic and endemic stemming from exposure of certain environmental risk factors in contextual sites (household and community levels) in which mothers are forced to give birth and raise their children. From the literature review infections (environmental factors), low birth weight-prematurity, birth asphyxia, tetanus and malnutrition were leading factors of infant mortality rate, indicating an urgent need for efficient prenatal care and public health services in the country. Maternal education has been reported as the most significant determinant in child survival rates. In other words there is a direct relationship between child survival and mothers' education. The pathways by which maternal education enhances child survival are interwoven with decisions and actions mothers take in health situations as their educational qualifications improve. Consequently, the relationship between maternal education and child survival was advocated as a strategy and a measure to reduce infant morbidity and mortality rate [20]. However, [21] disagree with this. The irony out of the above contradictory findings between mothers' education and child mortality were evidence of environmental conditions; lack of clean water, lack of portable water, poor hygiene and health care services and possession index under which children are reared. In areas where living conditions are lowest, infant mortality rate were found to "peak" [22]. Environmental or behavioral risk factors such as poor sanitation, insufficient waste disposal; poor domestic and human waste disposal, streams polluted with human wastes, an open toilet system, bushes littered with domestic wastes, no water drainage system (breeding grounds for mosquitoes), overcrowding in homes, poor basic health facilities or no breastfeeding in infancy leads to increased exposure to infections. Such synergisms are leading risk factors of high infant mortality rate. As the government acknowledged, "Nigeria would have to double its entire infrastructure for food production, health services, education, water supply, housing, energy, and services just to maintain today's low standard of living [19]. Scholer and Hickson, [16] also viewed mortality of the child as being influenced by other underlying factors of both biological and socio-economic, operating through proximate determinants. Blair [6] in a study, found dirty feeding bottles and utensils, inadequate disposal of household refuse and poor storage of drinking water to be significantly related to the high incidence of diarrhea. The belief that the measles attack is caused by enemies is common among polygamous family where co-wives are natural suspects. While measles is perceived as deadly disease among the Yorubas, diarrhea is perceived merely as a means of getting rid of body impurities or as a sign of 'teething', 'crawling', or 'stretching'. Also some mothers believe that diarrhea is caused by consumption of sweet things [17]. Mothers with this view will not likely introduce oral rehydration solution to their children since it contains sugar and salt. Despite the fact that the major childhood diseases have been identified and modern technology to combat them developed, children from African countries (Nigeria inclusive) die in large number from the attacks of these diseases [23]. The adduced reason is deeply rooted in people's beliefs and attitudes concerning childcare and behavioral practices into health strategies. The Nigerian Health Policy recognizes the need to reduce the current high infant mortality rates, but people's belief and behavioral practices have not been adequately integrated into the health intervention [23]. Other determinant factors reported globally include; maternal obesity $[9,24,25]$, diabetes $[19,26]$, hypertension [14, 23, 26], drinking of alcohol during pregnancy especially within the first trimester [27, 28], tobacco smoking during pregnancy [20] especially among singleton births [29]. Others include: HIV infection exposure [30] especially in developing countries [21], rural residence as well as Psychosocial Stressors [22].

\subsection{Prevention and Intervention}

\subsubsection{Infant Mortality and the Millennium Development Goals}

The poor level of maternal, newborn and child health shows that Nigeria needs focusing on Millennium Development Goals. In September 2000, the United Nations Millennium Declaration was signed by 189 countries. Its aim was that poverty eradication and sustainable development should be achieved in the world by 2015 [31]. This resolution listed a total of eight goals of which Goals 4 and 5 directly address the issues of infant and maternal mortality respectively. The current rates of maternal and newborn mortality put Nigeria way off-track to achieve Millennium Development Goals $4 \& 5$. Analysis of NDHS data shows that there has been no appreciable reduction in either underfive or infant mortality rates in Nigeria between 1990 and 2003. It is projected that if the current trend continues, Nigeria can only hope to achieve an under-five mortality of 176 per 100 live births by 2015 , more than twice the MDG target of 77 per 1000 live births.

\subsubsection{Prevention and Medical Treatments}

Reductions in infant mortality are possible in any stage of a country's development. Rate reductions are evidence that a country is advancing in human knowledge, social institutions and physical capital. Governments can reduce the mortality rates by addressing the combined need for education, nutrition, and access to basic maternal and infant health services. A policy focus has the potential to aid those most at risk for infant and childhood mortality allows rural, poor and migrant populations. Reducing chances of babies being born at low birth weights and contracting pneumonia can be accomplished by improving air quality. Improving hygiene can prevent infant mortality. Focusing on preventing preterm and low birth weight deliveries throughout all populations 
can help to eliminate cases of infant mortality and decrease health care disparities within communities. In the United States, these two goals have decreased infant mortality rates on a regional population; it has yet to see further progress on a national level [14]. Technological advances in medicine would decrease the infant mortality rate and an increased access to such technologies could decrease racial and ethnic disparities. It has been shown that technological determinants are influenced by social determinants. Those who cannot afford to utilize advances in medicine tend to show higher rates of infant mortality. Technological advances have, in a way, contributed to the social disparities observed today. Providing equal access has the potential to decrease socioeconomic disparities in infant mortality. Specifically, Cambodia is facing issues with a disease that is unfortunately killing infants. The symptoms only last 24 hours and the result is death. As stated if technological advances were increased in countries it would make it easier to find the solution to diseases such as this.

\subsubsection{Economic Policies}

As economy rises, so do technological advances and thus, medical advances in access to clean water, health care facilities, education, and diet. These changes may decrease infant mortality. Economically, governments could reduce infant mortality by building and strengthening capacity in human resources. Increasing human resources such as physicians, nurses, and other health professionals will increase the number of skilled attendants and the number of people able to give out immunization against diseases such as measles. Increasing the number of skilled professionals is negatively correlated with maternal, infant, and childhood mortality. Between 1960 and 2000, the infant mortality rate decreased by half as the number of physicians increased by four folds. With the addition of one physician to every 1000 persons in a population, infant mortality will reduce by $30 \%$. Infant mortality rate can be a measure of a nation's health and social condition $[4,5]$. It is a composite of a number of component rates which have their separate relationship with various social factors and can often be seen as an indicator to measure the level of socioeconomic disparity within a country. Industrialized countries have lower infant mortality rates than less developed countries. This is generally due to greater access to advanced medical technology, adequate sanitation, contraception, good nutrition for prenatal and postnatal care, and educational and informational awareness programs in developed nations.

\subsubsection{Aim of Study}

This study was focused on the Risk factors associated with infant mortality in Owerri metropolis, Southeastern Nigeria.

\section{Research Methodology}

\subsection{Study Area and Participants}

Owerri is the capital of Imo State in Nigeria, set in the heart of the Igboland. The two government hospitals in
Owerri metropolis; Federal Medical centre, (FMC) and Imo State Specialist hospital, were selected for the study. The population sample (200) comprised health workers in the selected hospitals.

\subsection{Study Design}

Descriptive research method was used for this study; the method is used to describe systematically, a situation or area of interest [32].

\subsection{Study Tool}

Well structured questionnaire was used to collect data as the research instrument. The questionnaire was formed under three subheadings: pre pregnancy factors, antenatal factors and post-natal factors. The following were considered in the study under pre-pregnancy factors: previous number of children, birth spacing, previous birth complications, HIV infection before pregnancy, malnutrition before pregnancy, alcohol intake before pregnancy, level of mother's education and previous caesarian section.

The following were considered in the study under ante natal factors: low birth weight, gestational diabetes, and failure to receive tetanus toxoid vaccine, congenital malformation, taking alcohol during pregnancy, smoking or staying near a smoker, malaria in mother and child, obesity and feeding habit of a pregnant woman.

The following were considered in the study under post natal factors; over weight of the baby, place of delivery, birth attendant, preterm birth, placenta abnormalities, caesarian section, failure to have a well baby check and jaundice.

In all the sections, respondents were asked to fill the blank spaces or tick against the alternative that best described their opinion about each of the issues raised. Two hundred questionnaires were administered to the respondents / participants on face to face basis; the questionnaire was collected on the spot.

\subsection{Ethical Permission}

This was obtained from the hospital management prior to data collection. Informed consent was also gotten from the voluntary participants/respondents.

\subsection{Data Presentation and Analysis}

The data that were generated were presented in tables and charts. Analysis of data was done using statistical method; percentages, and chi square at a confidence interval of $\mathrm{p} \leq 0$. 01 .

\section{Results}

Identified risk factors associated with infant mortality in Owerri metropolis Imo State are shown Tables below.

\subsection{Pre-pregnancy Factors}

The pre-pregnancy factors that are associated with infant 
mortality in Owerri metropolis are shown in Table 1 below.

Table 1. Pre-pregnancy factors that contribute to infant mortality.

\begin{tabular}{llll}
\hline & Number (\%) of responses & & Not in all cases \\
\hline Item & Yes & No & $62(31)$ \\
\hline Previous number of children & $100(50)$ & $38(19)$ & $56(28)$ \\
Birth spacing & $104(52)$ & $40(20)$ & $0(0)$ \\
Previous birth complications & $176(88)$ & $24(12)$ & $78(39)$ \\
HIV infection before pregnancy & $116(58)$ & $6(3)$ & $0(0)$ \\
Malnutrition before pregnancy & $170(85)$ & $30(15)$ & $50(25)$ \\
Alcohol intake before pregnancy & $80(40)$ & $70(35)$ & $30(15)$ \\
Level of mother's education & $144(72)$ & $26(13)$ & $90(45)$ \\
Previous caesarian section & $56(28)$ & $54(27)$ & $(2)$ \\
\hline
\end{tabular}

\subsection{Pre-pregnancy Maternal Health Problems}

Pre-pregnancy maternal health problems that contribute to infant mortality are shown in Table 2 below.

Table 2. Pre-pregnancy maternal health problems that contribute to infant mortality.

\begin{tabular}{ll}
\hline Item & Frequency \\
\hline Asthma & 110 \\
Epilepsy & 134 \\
Hypertension & 182 \\
Anemia & 194 \\
Heart problem & 110 \\
Thyroid problems & 100 \\
Depression & 138 \\
Anxiety & 76 \\
Mean & 65.3 \\
St. D & 20.26 \\
\%CV & 31.05 \\
\hline
\end{tabular}

$\mathrm{CV}$ : coefficient of variation

\subsection{Antenatal Factors}

The antenatal factors that are associated with infant mortality in Owerri metropolis are shown in Table 3 below.

Table 3. Antenatal factors that contribute to infant mortality.

\begin{tabular}{llll}
\hline & Number (\%) of responses & & Not in all cases \\
\hline Item & Yes & No & $92(46)$ \\
Low birth weight & $98(49)$ & $10(5)$ & $30(15)$ \\
Gestational diabetes & $168(84)$ & $4(2)$ & $0(0)$ \\
Failure to receive tetanus toxoid vaccine & $172(86)$ & $28(14)$ & $0(0)$ \\
Congenital malformation & $180(90)$ & $20(10)$ & $34(17)$ \\
Taking alcohol during pregnancy & $150(73)$ & $16(8)$ & $0(0)$ \\
Smoking or staying near a smoker & $170(85)$ & $30(15)$ & $0(0)$ \\
Malaria in mother and child & $200(100)$ & $0(0)$ & $120(60)$ \\
Obesity & $40(20)$ & $40(20)$ & $0(0)$ \\
Feeding habit of a pregnant woman & $178(89)$ & $22(11)$ & \\
\hline
\end{tabular}

\subsection{Post-Natal Factors}

The post natal factors that are associated with infant mortality in Owerri metropolis are shown in Table 4 below.

Table 4. Post-natal factors that contribute to infant mortality.

\begin{tabular}{llll}
\hline \multirow{2}{*}{ Item } & \multicolumn{2}{l}{ Number (\%) of responses } & Not in all cases \\
\cline { 2 - 4 } & Yes & No & $66(33)$ \\
\hline Over weight of a baby & $80(40)$ & $54(27)$ & $0(0)$ \\
Place of delivery & $180(90)$ & $20(10)$ & $0(0)$ \\
Birth attendant & $182(91)$ & $18(9)$ & $60(30)$ \\
Preterm birth & $130(65)$ & $10(5)$ & $38(19)$ \\
Length of labour & $140(70)$ & $22(11)$ & $0(0)$ \\
Placenta abnormalities & $190(95)$ & $10(5)$ & $0(0)$ \\
Caesarian section & $118(59)$ & $82(41)$ & \\
\hline
\end{tabular}




\begin{tabular}{llll}
\hline \multirow{2}{*}{ Item } & Number (\%) of responses & & Not in all cases \\
\cline { 2 - 4 } & Yes & No & $0(0)$ \\
\hline Failure to have a well baby check & $180(90)$ & $20(10)$ & $0(0)$ \\
Jaundice & $200(100)$ & $0(0)$ & \\
\hline
\end{tabular}

Table 5. Child health problems that contribute to infant mortality.

\begin{tabular}{ll}
\hline Item & Frequency \\
\hline Diarrhea & 180 \\
Acute respiratory infection & 150 \\
Measles & 166 \\
Malaria & 180 \\
Neonatal tetanus & 182 \\
Tuberculosis & 160 \\
Whooping cough & 150 \\
Bronchopneumonia & 174 \\
Meningitis & 142 \\
Mean & 82.44 \\
St. D & 7.55 \\
\%CV & 9.16 \\
\hline
\end{tabular}

\subsection{Hypothesis Testing}

Ho: antenatal risk factors associated with infant mortality do not contribute to infant mortality

Ha: antenatal risk factors associated with infant mortality contribute to infant mortality

Table 6. Hypothesis testing.

\begin{tabular}{lllll}
\hline Factors & $\chi \mathbf{2 c a l}$ & $\boldsymbol{\chi 2 \text { tab }}$ & Confidence interval & Hypothesis \\
\hline $\begin{array}{l}\text { Pre- } \\
\text { pregnancy }\end{array}$ & 324.72 & 32 & $\mathrm{p}=0.01$ & Ha accepted \\
Antenatal & 712.2 & 32 & $\mathrm{p}=0.01$ & Ha accepted \\
Post-natal & 642.2 & 32 & $\mathrm{p}=0.01$ & Ha accepted \\
\hline
\end{tabular}

Key:

$\mathrm{Ha}=$ Alternative hypothesis

$\mathrm{H}_{\mathrm{O}}=$ Null hypothesis

$\chi 2_{\text {cal }}=$ chi-square calculated and

$\chi 2_{\text {tab }}=$ chi-square tabulated

Decision rule: $\chi 2 \mathrm{cal}>\chi 2_{\text {tab }}$ we reject the null hypothesis and accept the alternative hypothesis and vice versa

\section{Discussion}

The findings from this survey using questionnaires are discussed below and recommendations made.

\subsection{Pre-pregnancy Factors}

From the statistical analysis of the results (Table 6), on pre-pregnancy factors that contribute to infant mortality, a high significance difference at $\mathrm{p} \leq 0.01$ was observed, indicating that pre-pregnancy factors as enumerated above contribute to infant mortality. Three of the pre-pregnancy factors seem to have high contributions above $70 \%$ to infant mortality in the study area; previous birth complication, malnutrition before pregnancy and the level of mother's education as opined by $72 \%$ of the respondents. This corroborates the findings of [18] and [20] who reported that the mother's educational attainment and literacy are correlated with age of first pregnancy and rate of infant mortality in different study areas. They consequently, advocated that the relationship between maternal education and child survival be used as a strategy and a measure to reduce infant morbidity and mortality rate.

Some other factors that received up to $50 \%$ reference as risks to child mortality were: HIV infection before pregnancy which is in line with previous studies of [21] and [30] which reported that HIV is a risk factor to infant mortality, birth spacing contributes to infant mortality as opined and previous number of children.

Previous caesarian section and alcohol intake during pregnancy may not always be implicated as risk factors to infant mortality in Owerri metropolis as both received less than $50 \%$ no from the respondents. However, previous studies [1, 32, 33], have reported that there is an association between infant mortality and alcohol consumption. Maternal health problems such as asthma $(10.5 \%)$, Epilepsy $(12,8)$, hypertension $(17.4 \%)$, anemia $(18.6 \%)$, heart problem $(10.5 \%)$, thyroid problem (9.6\%) depression (13.2\%), anxiety (7.3\%) were revealed as risk factors (at varying levels) associated with infant mortality.

\subsection{Antenatal Factors}

From Table 6, statistical analysis showed that antenatal factors studied significantly contribute to infant mortality in Owerri metropolis $(p \leq 0$. 01). All the respondents $(100 \%)$ agreed that malaria in mother and child can contribute to infant mortality. The other top (above 70\%) category of antenatal risk factors implicated were: congenital malformation, feeding habit of a pregnant woman, failure to receive TT vaccine by pregnant women, smoking or staying near a smoker during pregnancy corroborating the findings of $[20,29]$ as well as Gestational diabetes and taking alcohol during pregnancy confirming earlier reports [1].

The result of this study indicates that Obesity does not always contribute to infant mortality in Owerri metropolis as opined by $60 \%$ of respondents. This contradicts the previous studies of $[9,24]$.

\subsection{Post-Natal Factors}

Statistical analysis of results showed a high significant difference as $\mathrm{p} \leq 0.01$ indicating that the post- natal factors studied, greatly contribute to infant mortality in Owerri metropolis. All respondents agreed that Jaundice is serious risk factor that contribute to infant mortality as opined by $100 \%$ of the respondents. In the opinion of over $70 \%$ of the respondents, the following post natal factors pose great risks to infant mortality in the study area; Placenta abnormality was accepted by $95 \%$ of the respondents as being a risk factor associated with infant mortality. The result of this study also indicated that, caesarian section is a risk factor associated with infant. Place of delivery and failure to have a well-baby check contribute to infant mortality as agreed by 
$90 \%$ of the respondents. Length of labour was opined by $70 \%$ of the respondents as a risk factor associated with infant mortality. Sixty five percent of the respondents agreed that a birth attendant and preterm birth are risk factors to infant mortality. Khashu [17] has also earlier implicated preterm birth as risk factors to infant mortality. The weight of a baby is also indicated as one of the risk factors though at low rate (less than 50\%). Studies have reported low birth weight as a contributory to infant mortality $[17,18]$.

Neonatal/infant diseases such neonatal tetanus (12.3\%), malaria (12.1\%), diarrhea $(12.1 \%)$, bronchopneumonia (11.7\%), measles (11.2\%), tuberculosis (10.8), acute respiratory infection $(10.1 \%)$,), whooping cough $(10.1 \%)$, and meningitis $(9.6 \%)$ were also revealed to be risk factors associated with infant mortality to varying extent. Neonatal tetanus seems to be the most implicated while meningitis is the least implicated.

The percentage co-efficient of variation $(\% \mathrm{CV})$ of the child health problems associated with infant mortality was $9.16 \%$. This figure implies that there is a moderate variation among the child health problems that contribute to infant mortality in Owerri metropolis.

\section{Conclusion}

From the findings of this study, it is obvious that various pre- pregnancy factors, antenatal factors and post-natal factors contribute to infant mortality in Owerri metropolis. The level of significance of these factors is quite high $(\mathrm{p} \leq 0$. 01). However, these risk factors can be curbed with concordant reduction in infant mortality rate.

Reduction in infant mortality are possible in any stage of a country's development. Rate reductions are evidence that a country is advancing in human knowledge, social institutions and physical capital. Governments can reduce the mortality rates by addressing the combined need for education, nutrition, and access to basic maternal and infant health services. A policy focus has the potential to aid those most at risk for infant and childhood mortality allows rural, poor and migrant populations.

Reducing chances of babies being born at low birth weights and contracting pneumonia can be accomplished by improving air quality and hygiene. Focusing on preventing preterm and low birth weight deliveries throughout all populations can help to eliminate cases of infant mortality and decrease health care disparities within communities [14]. Technological advances in medicine and an increased access to such technologies could decrease the infant mortality rate. It has been shown that technological determinants are influenced by social determinants. Those who cannot afford to utilize advances in medicine tend to show higher rates of infant mortality. Technological advances have, in a way, contributed to the social disparities observed today. Providing equal access has the potential to decrease socioeconomic disparities in infant mortality. A deliberate public awareness programme as well as policy on measures to limit these risk factors, should be put in place and enforced. These are expected to in-turn reduce infant mortality rate drastically in the State and nation as a whole.

\section{References}

[1] B. Alm, G. Winnergren, G. Norvenius and K. Helweglarsen, "Caffeine and Alcohol as Risk factors for Sudden Infant Death Syndrome, ”Nordic Epidemiological SIDS Study, Arch Dis. child, 81 (2): 107-111, 1999.

[2] Center for Disease Control and Prevention, "Infant Mortality," www. gov/reproductivehealth/maternalinfanthealth/infantmortality. $\mathrm{htm}$, August 12, 2014.

[3] T. O. Lawoyin, "Risk Factors for Infant Mortality in a Rural Community in Nigeria," The Journal of the Royal Society for the Promotion of Health 121 (2):114-118, 2001.

[4] O. O. Ayoola, "A Five year Childhood Mortality of the University College Hospital, Ibadan, Nigeria," West Africa Journal at Med, 24 (2):175-179, 2005.

[5] B. Larroque, G. Breart, M. Kaminski, M. Dehan, M. Andre, A. Burguet, H. Grand Jean, B. Ledesert, C. Leveque, F. J. Mailard, "Survival of very Preterm Infants, " A Pop Based Cohort Study, 89 (2):139- 144, 2004.

[6] P. S. Blair, P. J. Flemming, D. Bensley, I. Smith and C. Bacon, "Smoking and the Sudden Infant Death Syndrome: Results from 1993-5 Case Study for Confidential inquiry into Stillbirths and Deaths in infancy," BMJ, 27; 313 (7051): 195198, 1996.

[7] M. Norton, "New Evidence on Birth Spacing: Promising findings for Improving Newborn, Infant, Child, and Maternal Health," International Journal of Gynecology \& Obstetrics 89: $1-6,2005$.

[8] National Center for Health Statistics. National Vital Statistics Reports (NVSR). Deaths: Final Data for 2011.

[9] N. J. Sebire, M. Jolly, J. P. Harris, J. Wadsworth, M. Joffe, R. W. Beard, L. Regan, and S. Robinson, "Maternal Obesity and Pregnancy Outcome; A Study of 287, 213 pregnancies in London, " Int. J. Obes Relat. Metab. Disord, 25 (8):175- 1182, 2009.

[10] World Health Organization, "Maternal Anthropometry for Prediction of Pregnancy Outcome: Memorandum for a USAID/WHO/PAHO Mother Care Meeting," Bulletin of the World Health Organization, 69:523-532, 1991.

[11] T. D. Clause and E. Mathersen, "Poor Pregnancy Outcome in Women with Type 2 diabetes," Diabetes care 28 (2): 323-328, 2005 .

[12] M. F. MacDorman and T. J. Mathews, "The Challenge of Infant Mortality, Have We Reached a Plateau," Public Health Reports, 124, 2009.

[13] E. Rey and A. Couturier, "Prognosis of Pregnancy in Women with Chronic Hypertension," Am. J. Obstet Gynecol, 171 (2); 410-416, 1994.

[14] T. J. Mathews and M. F. MacDorman, "Infant Mortality Statistics from 2006 Period linked Birth/infant Death data set," Nathvitalstat. Rep, 30; 58 (17): 1-31, 2010. 
[15] S. J. Scholer, G. B. Hickson and W. A. Ray, "Socio demographic factors identify US infants at High risk of Injury Mortality," Paediatrics 103 (6): 1183-1188, 1999.

[16] M. Khashu, M. Narayanan, S. Bhargava and H. Osiovic, "Prenatal Outcomes associated with Preterm Birth a 33 to 36 weeks gestation," A pop. Based cohort study, 123 (1): 109113, 2009.

[17] J. Zeitlin, M. EI Ayoubi, P. H. Jarreau, E. S. Draper, B. Blondel, W. Kunzel, M. Cuttini, M. Kaminski, L. Gortner and P. Van Reempts, "Impact of Fetal Growth Restriction on Mortality and Morbidity in a very Preterm Birth Cohort," J. Pedatr, 157 (5): 733-739, 2010.

[18] M. C. Macintosh, K. M. Fleming, J. A. Bailey, P. Doyle, J. Modder, D. Acolet, "Perinatal Mortality and Congenital Anomalies In Babies of women with type 1 or 2 Diabetes in England, Walles and Northern Ireland," BMJ 22- 333, 2006.

[19] K. Wisborg, U. Kesmodel, and T. B. Henrikesen, "Exposure to tobacco smoke in utero and the risk of stillbirth and death in the first year of life," Am J. Epidermiol, 15; 154 (4): 322-327, 2000 .

[20] P. Brocklehurst and R. French, "The Association between Maternal HIV Infection and Perinatal Outcome: A Systematic Review of the Literature and Meta-analysis," J. Obsteric. Gynaecol, 105 (8): 836-848, 1998.

[21] Z. C. Luo, R. Wilkins, M. S. Kramer, "Fetal and Infant Health Study Group of the Canadian Perinatal Surveillance System. Disparities in Pregnancy outcome according to Marital and Cohabitation status," Obstet. Gynecol, 103 (6): 1183-1188, 2004.

[22] M. Vanek, E. Sheiner, A. Levy, M. Mazor, "Chronic Hypertension and the Risk for Adverse Pregnancy outcome after Super Imposed Pre-Eclampsia,” Int. J. Gynaecol. obstet, 86 (1): 7-1, 2004.

[23] E. A. Nohr, M. Vaeth, B. H. Bech, T. B. Henriskseri, S. Cnattingius, J. Olsen, "Maternal Obesity and Neonatal Mortality according to subtype of Preterm Birth, " Obstet. Gynecol, 110 (5): 1083-1090, 2006.

[24] J. Kristiansen, M. Vestergaard, K. Wisborg, U. Kesmodel, and N. J. Secher, "Pre-Pregnancy Weight and the Risk of Still Birth and Neonatal Death," Int J of obstetrics and Gynecology, vol. 112: 403-408, 2005.

[25] U. M. Reddy, S. K. Laughon, L. Sun, J. Troendle and M. Willinger, "Pre-Pregrancy risk Factors for Ante Partum still Birth in the United State," Obstet. Gynecol, 166 (5): 1119$1126,2010$.

[26] U. Kesmodel, K. Wisborg, S. F. Olsen, T. B. Henriksen and N. J. Secher, "Moderate Alcohol Intake in Pre-Pregnancy and the Risk of Spontaneous Abortion," Alcohol 37 (1): 87-92, 2002.

[27] G. C. Windham, J. Von Behren, L. Fenster and C. Schaefer, "Moderate Maternal Alcohol Consumption and Risk of Spontaneous Abortion,” Epidemiology, 8 (5): 509-514, 1997.

[28] H. Pollack, P. M. Lantze, J. G. Frohna, "Maternal Smoking and Adverse Birth Outcomes among Singletons and Twins," Am J Public Health, 90 (3): 395-400, 2000.

[29] K. K. Venkatesh, G. De Bruyn, E. Marinda, K. Otwombe and R. Van Niekerk, "Morbidity among Infants born to HIVinfected Women in South Africa: Implication for Child Health in Resource-limited Setting,” J. Trop Pediatr. 57 (2): 109-19, 2011.

[30] R. Farmer, D. Miller and R. Lawrensen, Epidemiology and Public Health Medicine, $4^{\text {th }}$ Edition. Paris: Blackwell Science Ltd, 1996, pp. 3-106. 